Review

\title{
Importance and Applications of Robotic and Autonomous Systems (RAS) in Railway Maintenance Sector: A Review
}

\author{
Randika K. W. Vithanage *(1), Colin S. Harrison and Anjali K. M. DeSilva \\ Department of Mechanical Engineering, Glasgow Caledonian University; Glasgow G4 0BA, UK \\ * Correspondence: Randika.Vithanage@gcu.ac.uk
}

Received: 19 June 2019; Accepted: 25 July 2019; Published: 30 July 2019

check for updates

\begin{abstract}
Maintenance, which is critical for safe, reliable, quality, and cost-effective service, plays a dominant role in the railway industry. Therefore, this paper examines the importance and applications of Robotic and Autonomous Systems (RAS) in railway maintenance. More than 70 research publications, which are either in practice or under investigation describing RAS developments in the railway maintenance, are analysed. It has been found that the majority of RAS developed are for rolling-stock maintenance, followed by railway track maintenance. Further, it has been found that there is growing interest and demand for robotics and autonomous systems in the railway maintenance sector, which is largely due to the increased competition, rapid expansion and ever-increasing expenses.
\end{abstract}

Keywords: robotics; autonomous systems; railway; maintenance

\section{Introduction}

Maintenance can be defined as a task or series of tasks that protect or reinstate the anticipated condition of a system, and these tasks include technical, administrative, and managerial actions taken [1,2]. In railway industry, proper maintenance of infrastructure, rolling-stock, and other resources are vital in providing a safer, reliable, efficient, and resilient output. In Swedish railway, about 30\% of all rail and track related incidents and accidents that took place between 1988 to 2000 were due to maintenance related causes [3]. Additionally, it has been revealed that among 700 accidents reported over 23 countries, $37 \%$ were due to rolling-stock faults and $36 \%$ were due to failures in infrastructure [4]. Further, by referring to Pareto graph in Figure 1a, it can be realized that maintenance contributes to most $80 \%$ of the rail and track related accidents in Sweden. In addition, by referring to the Pareto graph in Figure $1 \mathrm{~b}$, it is evident that rolling-stock and infrastructure faults contributed almost $80 \%$ of accidents summarized by the D-RAIL FP7 project. 


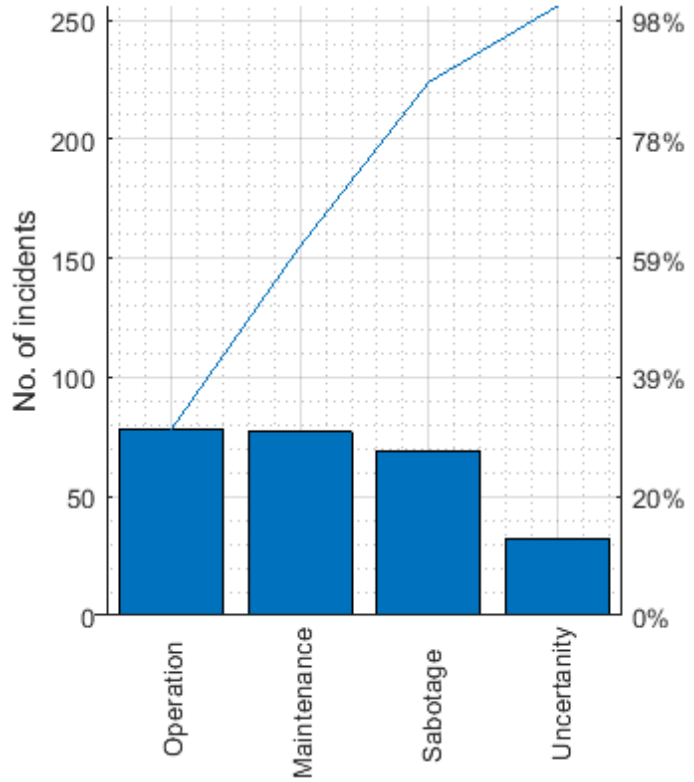

(a)

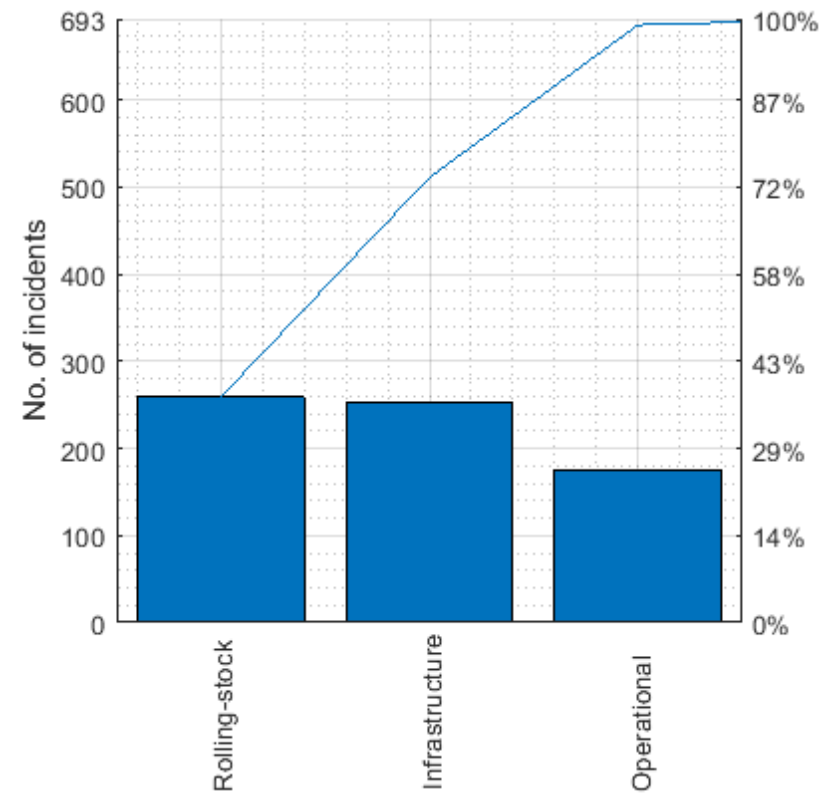

(b)

Figure 1. (a) Rail and track related incidents and accidents in Swedish railway [3] and (b) Railway accidents considered by cause in the D-RAIL FP7 project [4].

In addition, railway maintenance tasks are costly, and poor maintenance or failure to conduct preventive maintenance will lead to expensive consequences $[5,6]$. According to the joint report that was published by the United Kingdom's (UK's) Department for Transport and the Office of Rail Regulation Network, rolling stock maintenance in the country accounted $£ 0.4 \mathrm{bn}$, which is around $3 \%$ of the total railway expenditures in 2009-2010 and a typical rolling-stock maintenance would cost about $44 \%$ of its whole life costs [7]. Based on the report that was published by National Audit Office, UK in 2015, the annual maintenance expenditures of UK's rail infrastructure exceeds $£ 1$ bn and in 2013-2014 and more than two-thirds of 25,531 employees in Network Rail, UK were placed on maintenance related jobs [8].

Further, the maintenance cost in Europe railway ranges from $€ 30,000$ to $100,000 \mathrm{~km} / \mathrm{year}$ [9]. In the UK, it has been suggested that about $20 \%-30 \%$ of the service life maintenance cost of a passenger rolling-stock is associated with wheelset maintenance [10]. On the other hand, inadequate maintenance will reduce the reliability of services, and this leads to delays, train cancellations, and customer dissatisfactions [9]. Based on past data, about $23 \%, 17 \%$, and $10 \%$ of the UK wide train delays were taken place due to rolling-stock faults, track faults, and power/signal faults, respectively-which could have been reduced or avoided by preventive maintenance [11].

\section{Importance of Robotic and Autonomous Systems (RAS) in Maintenance}

Railway companies drive towards continuous improvements of existing infrastructure, fleets, resources, and processes due to increased competition and rapid expansion. For example, it is projected to increase the UK's national rail traffic in passenger miles by $100 \%$ over the next 30 years, resulting in an increase of 11,566 rolling-stock fleets in 2046 when compared to 2017 [12]. Therefore, optimizing inspection and repair of the rail network, facilities, and rolling-stocks in a cost-effective manner, whilst preserving or enhancing the safety, quality, and reliability of the service remains a key challenge [13]. For instance, Office of Rail and Road, UK expects Network Rail to carry out its maintenance $17 \%$ more efficiently by the end of 2019. Further, to reach efficiency targets, the Network Rail plans to reduce its maintenance staff by $8 \%$ over the 2014-2019 control period [8]. 
On the other hand, the RAS are becoming economical and feasible with recent manufacturing and technological advancements. For example, over the period of 15 years from 1990, the mean quality adjust price of industrial robots in the UK, United States (US), and European Union (EU) has dropped down by nearly 80\% [14] — shown in Figure 2a. According to the World Robotics 2014 data, annual shipments of industrial robots have increased over time, despite the drastic drop in 2009, which was due to world's economic recession, see Figure 2b. Further, as shown in Figure 2b, it can be seen that the same trend exists within the UK [2]. Therefore, the introduction of RAS in railway maintenance would be an ideal solution for achieving expected cost benefits. Atherton et al. have conducted an in-depth financial and technical study to evaluate the feasibility of introducing RAS into rolling stock fluid service tasks. Here, they have concluded that an autonomous approach will double the throughput of fluid service task for only about $15 \%$ of the cost of an equivalent manual servicing facility [15].

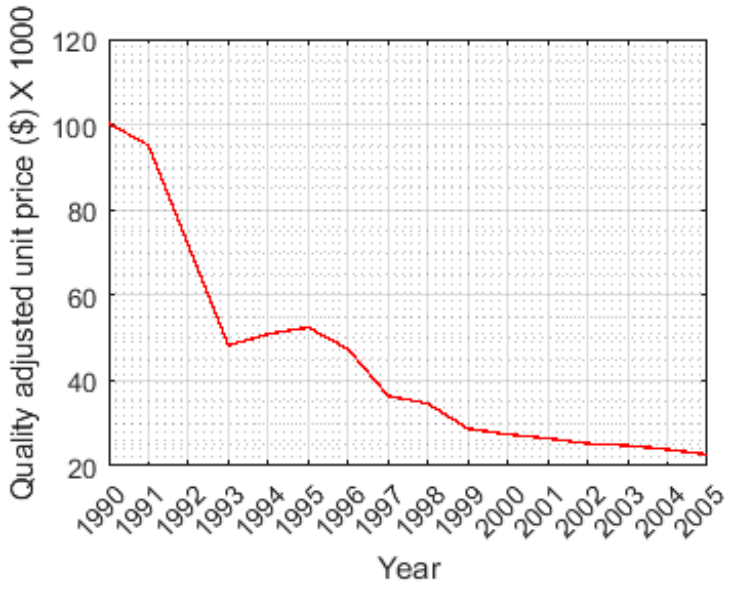

(a)

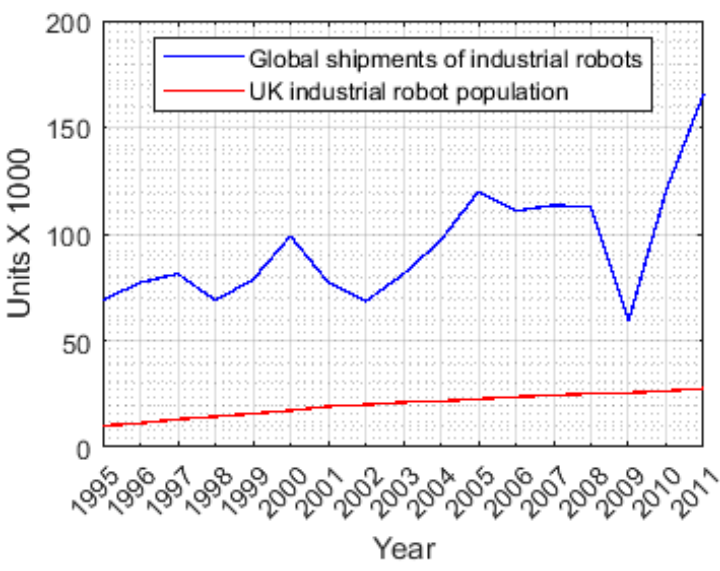

(b)

Figure 2. (a) Price of industrial robots over time [1] and (b) population in the United Kingdom (UK) and annual shipments of industrial robots from 1995 to 2011 [2].

In addition, railway maintenance technicians risk own safety to assure the safety of passengers and to keep trains operating. In most occasions, these railway employees perform their jobs in unfavourable and unergonomic environments. For instance, railway track maintenance technicians and engineers that are constantly exposed to severe weather conditions and encounter risks while working on active railway tracks with live power transmission lines/rails in the vicinity, trains travelling at high speeds from adjacent tracks, working at heights, or in unergonomic postures for prolonged periods [16,17]. In addition, the workers in rolling-stock maintenance and service within depots face a similar amount of risks. For example, in the UK, the cab front cleaning is manually conducted, which exposes workers to highly dampened environments close to high voltage overhead power lines or electrified third rails [18]. Another hazardous rolling stock maintenance task is transmission fluid changing process, where technicians need to execute the bulk of work beneath rolling-stock in unergonomic environments, while getting exposed to hazards, such as oil spill slip/trip risks or working too close to electrified third rails [14]. Therefore, the introduction of RAS to such dull, dirty, and dangerous maintenance tasks could potentially minimize the health and safety risks on technicians.

The majority of railway maintenance tasks are monotonous and possibly depend on attitude and self-discipline of technician towards the job [19]. When considering Japanese high-speed railway track maintenance- which involves a train driver and a supervisor who perform well defined simple series of tasks over a prolonged period, where it is easy to lose focus and motivation to accomplish an immaculate job [19]. Besides, human errors are inevitable. Such human errors in the railway include disassembly errors, inspection errors, assembly errors, decision-making errors, and installation errors. Human errors can cause disastrous failures, and subsequently the loss of lives [20]. In 
contrast, present-day robots and autonomous systems are renowned for their high accuracy and path repeatability. Therefore, railway companies should consider such capabilities and utilize RAS to handle monotonous or non-value-added maintenance tasks and utilize railway technicians to do advanced, challenging, and value-added tasks.

Further, it has been revealed that rolling stock maintenance could be clustered and distributed over local contractors. This will encourage them to be specialists in the field, and apply techniques to achieve increased productivity through automation [21]. Additionally, it has been identified that increased automation is a key objective in the Rail Technical Strategy 2012, and it is expected to obtain operational cost benefits by intelligent maintenance techniques [22,23]. Therefore, the introduction of autonomous systems in order to eliminate or minimize human intervention in maintenance processes would be an ideal technique, and it can be viewed that the railway industry in the UK, including many other countries, is in the right stage to invest in automation [24,25].

\section{RAS in Railway Maintenance}

For decades, researchers have conducted extensive studies to introduce RAS into railway maintenance tasks. For example, in 1987, Martland analysed how robotics could affect the locomotive rebuilding at Conrail's Juniata locomotive rebuilding shop, where he has taken more than two dozen of processes into consideration. Through this study, he has concluded that there is only limited potential for improving the productivity of the rail workshop through RAS and it will remain modest until equipment and technology become economical [26]. In contrast, another feasibility study that was conducted by Wiercienski and Leek two years later has concluded that the use of robots to clean the undersides of Toronto subway cars is viable, both technically and economically. They have proposed a system that includes three industrial robots and an industrial vision system to wash undersides of two subway cars simultaneously [27].

In this paper, more than 65 authentic research articles that were related to distinct research and developments of RAS in railway maintenance domain have been summarized and analysed. It has been identified that majority of examined developments are related to rolling-stock maintenance and inspection, which is about $56 \%$. About $28 \%$ developments are related to rail-track maintenance and inspection tasks, followed by power transmission maintenance, which is around $5 \%$. RAS in the railway bridge and tunnel maintenance accounted $4 \%$ and $3 \%$ of total developments, while other maintenance applications, such as automated condition monitoring of grade crossings and cleaning of stations and platforms accounted for $4 \%$ of the total developments-see Figure 3. Further, it has been found that the majority of RAS implemented are limited to inspection and monitoring tasks, which are about $62 \%$. The remaining $38 \%$ of RAS perform physical manipulation-see Figure 4 for a detailed breakdown by area of application.
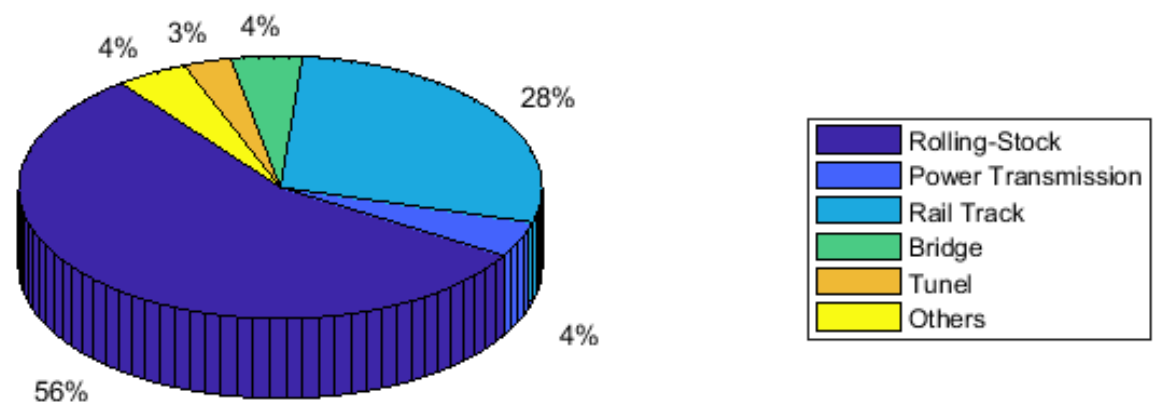

Figure 3. Development of Robotic and Autonomous Systems (RAS) in railway maintenance by the application. 


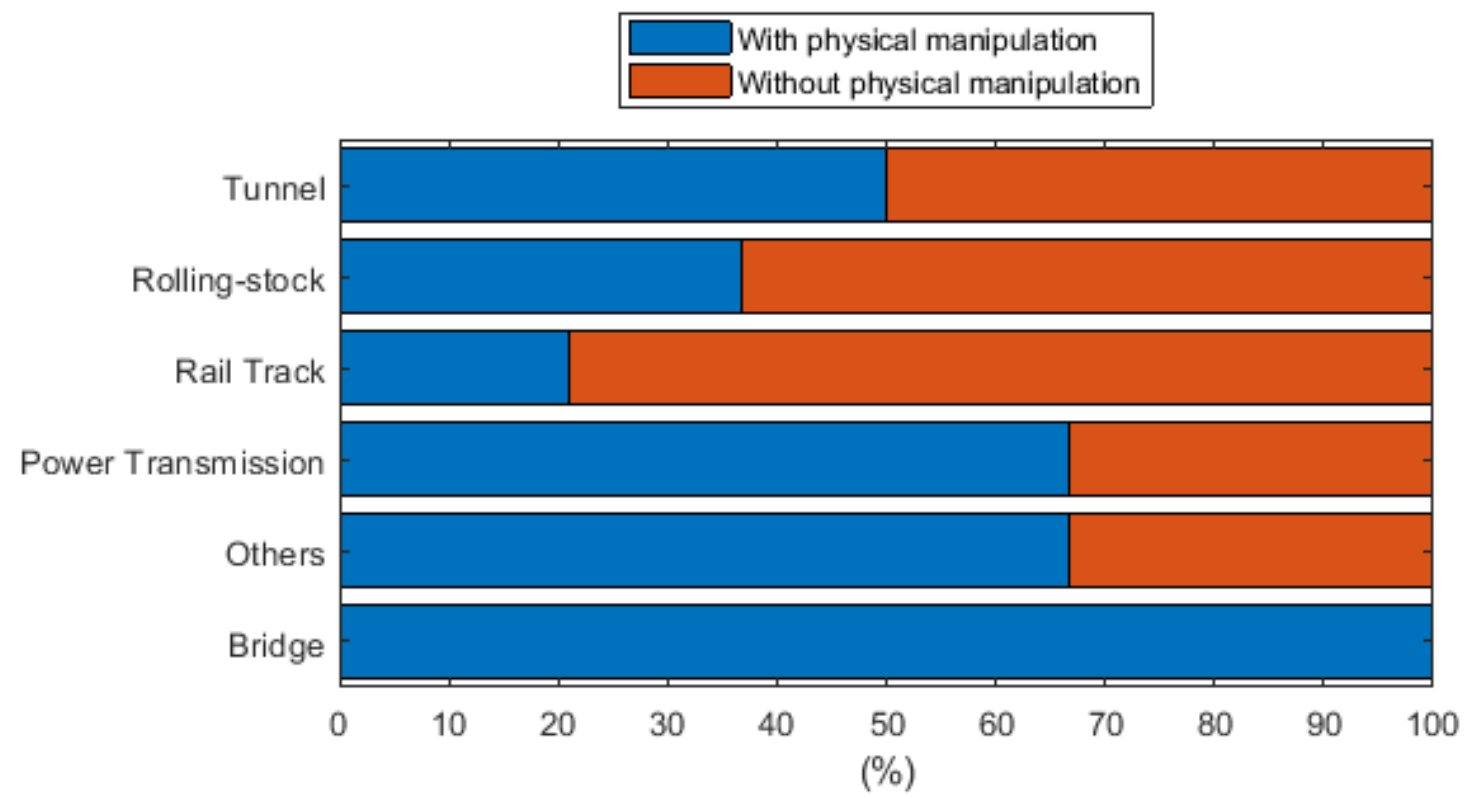

Figure 4. Segregation of RAS developments in railway maintenance by nature of task.

\subsection{RAS in Rolling-Stock Maintenance}

As summarized in Figure 5, 36.8\% RAS developed for rolling-stock maintenance intends to execute physical jobs, while the other $63.2 \%$ does not perform any physical manipulation. Further, RAS, which are under study or fully developed for rolling-stock inspection and monitoring accounts for about $60 \%$ of all RAS developed for rolling-stock maintenance tasks, followed by systems for rolling-stock cleaning, which is $16 \%$. RAS applications in rolling-stock fluid servicing tasks account for $11 \%$ of all rolling-stock related RAS developments, and the remaining 13\% of the applications consists of rolling stock rebuilding and other applications, such as augmented and virtual reality, to assist and train maintenance workers-see Figure 5.
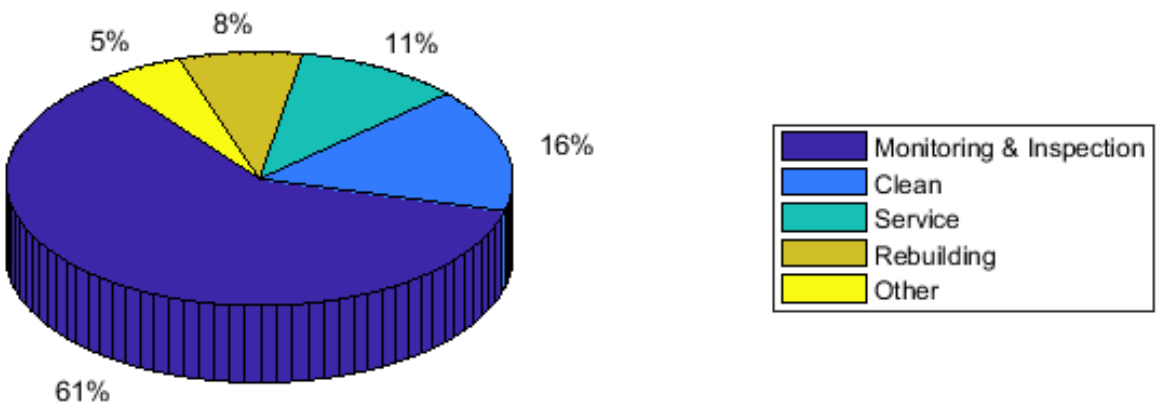

Figure 5. Breakdown of RAS in rolling stock maintenance by area of application.

\subsubsection{RAS in Rolling-Stock Cleaning}

Hiroshi Yaguchi [28] has successfully introduced two robots to clean rolling-stock in East Japan Railway company, one to clean commuter rail car floors and another to clean the bonnet of Shinkansen, high-speed Japanese trains. A mobile robot is developed to clean the commuter rail car floors in conjunction with Toshiba Co. Ltd. The developed robot weighs approximately $93 \mathrm{~kg}$, which consists of ultrasonic sensors and encoders for navigation, and optical and touch sensor for safety. This robot can be operated in both automatic and manual modes, and its capabilities include sweeping the floor, collecting dirt, sprinkling water, mopping the floor, pulling dirty water, and polishing the floor. The robot takes about $15 \mathrm{~min}$. to clean a single car. The navigation of robot is done by dead reckoning - tracking the desired path and its position by encoder data, while any positional error is 
corrected using distance sensors [28]. The second robot is developed to clean the Shinkansen train bonnet with the collaboration of Uchida Oil Hydraulics Mfg Co. Ltd. and ShinMaywa Industries Ltd. Previously, the cleaning process of Shinkansen bonnet was carried out by six maintenance workers. The design challenges of the robotic system included demand for a large work envelope, compact rest position, and ability to move along and lateral directions to the train. Therefore, researchers have designed an eight-axis articulated robot mounted on a mobile platform that was capable of moving along the full-length of a Shinkansen train and across three service bays in the lateral direction. The main control method of the robot was point-to-point teaching and playback. Hiroshi has concluded the main challenges in both RAS applications to be cost and ability to sense environment/target effectively [28].

A self-traction-model to clean urban mass transit vehicles was proposed by $\mathrm{Xu}$ et al. The washing apparatus is mounted on a mobile vehicle platform, which is driven by a variable speed and voltage inverter. The motion and path planning of the manipulator is achieved by the neutral cell self-adaptive and Cross-Coupling Control algorithm. Further, a novel variable water control algorithm is incorporated into the system to make it energy and water efficient. The researchers claim that the system has gone through years of testing in various depots and was proven to work efficiently and robustly [29]. Further, there are some conceptual designs and ongoing research to introduce RAS in rolling-stock cleaning tasks. For example, Tomiyama et al. [30] have presented a systematic analysis of the train cab front cleaning task and generated subclasses that will enable researchers to efficiently and effectively find solutions to each sub-task. Further, this study presents several conceptual designs of cab front cleaning robots and two illustrations of robotic arms are provided. In contrast to Hiroshi Yaguchi's bonnet cleaning robot, Tomiyama et al. have divided the work envelope into two along the vertical symmetric line of the train and positioned two identical robots in each side [28,30]. Furthermore, Moura and Erden [18] presented a theoretical control and path planning methodology for a train cab front cleaning robot by exploiting the operational space formulation and simultaneous force and position control introduced by Khatib [31,32].

\subsubsection{RAS in Rolling-Stock Fluid Servicing}

Thus far, the authors were unable to locate a RAS, which is successfully implemented in a rolling-stock fluid changing task. However, there are several ongoing studies to introduce RAS in rolling-stock fluid changing tasks. Atherton et al [15] have conducted a technical feasibility study in introducing RAS to passenger train fluids, such as fresh water, coolant, screen wash, fuel, effluent, and wheel sand servicing tasks. One of the challenges identified in this research is the different sizes and the positioning of fluid ports in fleets. Through this study, it has been concluded that the implementation of RAS in passenger train fluid servicing task is viable. Further, two preliminary conceptual designs, which consist of a Cartesian robot and an articulated robot, are proposed.

Further, Farnsworth and Tomiyama [33] looked into automated transmission fluid changing task of rolling stock with an industrial engineering aspect. They have introduced a novel methodology to capture, classify, and design automated platforms for industrial maintenance based on a case study that was conducted on Bombardier Class 222 diesel train transmission fluid changing process. In contrast, work that was carried out by Vithanage et al. [14] emphasizes the technical aspect of the gear fluid changing tasks as compared to other high-level investigations conducted. Through this research, they have successfully adopted Aggregated Channel Feature, an advanced machine learning algorithm to detect the drain and filler plugs of Siemens Class 380 rolling-stock main gearbox and curved coupler. Further, they have fused multiple sensors and introduced an Artificial Neural Network, which consists Levenberg-Marquardt learning algorithm to localize relatively smaller components in partially organised worlds, such as railway maintenance depots with $\pm 1 \mathrm{~mm}$ accuracy [34]. 


\subsubsection{RAS in Rolling-Stock Inspection}

Rolling-stock inspection is expensive, labor-intensive, and critical for safe operation. Therefore, certain inspection tasks have been automated over the past several decades. For example, the implementation of wayside detectors, cameras mounted to the rolling-stock undercarriage, and automated inspection tasks in maintenance depots [35]. In most cases, rolling-stock wheels and bearings are responsible for derailments [36]. Therefore, a number of automated wayside detectors are designed and developed to overcome this issue. In Conrail, the derailments due to defects in the wheels were reduced almost $50 \%$ by introducing wayside detectors [36]. Papaelias et al. have proposed a rolling-stock wheel and axle bearing monitoring system that is based on high-frequency acoustic emission and vibration analysis mounted to a train. The study has found that it is viable to detect and classify axle bearing defects by integrating high-frequency acoustic emission data with vibration data based on their severity [4]. However, these wayside monitoring systems need to be robust and withstand harsh weather conditions. Therefore, Asplund et al. have tested an automatic laser-based wheel profile monitoring system (WPMS) for accuracy and performance in extreme weather conditions. The study shows that laser-based WPMS indicates a deviation of less than $0.2 \mathrm{~mm}$ for the flange height, $0.3 \mathrm{~mm}$ for the flange thickness, and $0.32 \mathrm{~mm}$ for the flange slope as compared to measurements collected through handheld MiniProf measurement equipment [37].

Hart et al. have proposed a multi-spectral rolling-stock undercarriage inspection technique that combines visible and infrared images, which allow for recording both physical and thermal conditions, and the correlation between two. The scope of this study includes the monitoring and inspection of disc brake condition, bearing performance, and detection of any anomalies in electrical systems, such as induction motor and air-condition unit [38]. A similar thermal imagery approach is used by Deilamsalehy et al. to detect sliding wheels and hot bearings. The proposed methodology consists of a wheel and bearing detection module, hot bearing detection module using thresholding, and a Support Vector Machine (SVM) classifier, which uses a Histogram Oriented Gradient (HOG) of thermal images as input to detect flat wheels. The developed system is capable of detecting simulated and real-world defective wheels, with $98 \%$ accuracy [39]. Furthermore, a study has been conducted to determine the feasibility of inspecting rail underframe components of freight cars, such as center sill, side-sills, and cross-bearers. The study has proposed both a hardware and software to collect the required visual data and detect and assess rail undercarriage components for any deformation or buckling and presence of breaks or cracks. The study concludes that presented image acquisition and machine vision algorithms demonstrated the feasibility of automating the inspection of structural components [40].

Liu et al. have proposed an automated status inspection of fastening bolts on freight trains while using machine vision. The developed algorithm delivered the best performance by combining gradient orientation co-occurrence matrix and SVM classifier. The system is able to detect the existence or nonexistence of a bolt in a complex environment with $99.96 \%$ accuracy and it is expected to evaluate the performance of the system in adverse weather conditions [41]. In addition, Li et al. have proposed another automatic bolt defect recognition system - which focuses on freight train wheels. Similar to the method that was proposed by Liu et al., they have utilized the SVM classifier to distinguish the presence or absence of a bolt. In contrast, Li et al. have used a binary pattern descriptor as input to the classifier and their system consists of a self-updating scheme, which automatically captures various real-life scenarios. The system, as presented by Li et al., has demonstrated $100 \%$ bolt defect detection rate with $8.1 \%$ false alarm rate [42].

Additionally, Kim and Kim have proposed an automatic system that accurately measures brake shoe thickness with an accuracy of $0.654 \mathrm{~mm}$. They have successfully exploited the shadow regions between the brake shoe and wheels that look similar in all images to localize the brake shoes by modeling the boundaries as inverse polynomials [43]. Furthermore, Zhou et al. have presented a real-time automated visual inspection system of angle cocks, which is a critical component of a rolling-stock brake system. The developed system incorporates a gradient encoding histogram and SVM in the processing module. It has been claimed that the system achieves $99.8 \%$ accuracy in fault 
detection [44]. In addition, the Bombardier team at Midrand, South Africa has commissioned an Automatic Vehicle Inspection System (AVS), together with expertise in MRX technologies and IBM, which is proven to be extremely successful. The system is capable of monitoring multiple aspects, such as brake pad and disc conditions, axle temperature, wheel profile, wheel damage, pantograph wear, and any abnormalities on train exterior profile while using cutting-edge three-dimensional (3D) image acquisition and processing tools [45].

Edwards at al. and Liu et al. have presented online visual inspection systems that capable inspecting rail car safety appliances and bogie block keys of freight trains respective. Both systems utilize machine vision, advanced image processing algorithms, and state of the art machine learning algorithms to identify the defects [46,47]. Besides, Vithanage et al. have presented an image processing system to identify and localize the connector pins of Scharfenberg type automatic couplers mounted on Siemens Class 380 trains. The system claims to have high detection rate and robustness to environmental noises. The proposed system expects containing an off the shelf industrial robot to execute the inspection process [14]. This is system was further developed to have a unified 3D vision and a force-position controller. The prototyped work cell is validated while using an industrial grade 6-DoF articulated robot. It has been estimated to improve the standard operating time by approximately $34 \%$ [48].

\subsection{RAS in Rolling-Stock Rebuilding}

Kent and Ward have carried out some early development work to introduce robotics into the additive repair of rolling-stock wheels, which is supported by the Rail Safety and Standards Board (RSSB) via Rail Research UK Association (RRUKA) [10]. However, as an intermediate output, they have proposed a rolling-stock wheelset inspection robotic cell that consists of a 6 DoF articulated Kuka robot mounted on a rail, ToF sensor, RGB sensor, and a train wheel rotating mechanism. In addition, the mining company Vale, Brazil has invested on a robotic rail car rebuilding cell. According to the manager, operational improvements at Vale, maintenance cycle time was reduced from 48 hours per car to 11 hours per car on average. Further, they have managed to remove technicians from labour intensive and dangerous work, and assign them to safer and more value-added tasks [49]. A commercial rolling-stock wheel set maintenance shop at "SIMMONS Machine Tool Corporation" utilizes reprogrammable robots and overhead gantry system to automate the movement of the wheel sets and their components between various workstations and machines. The system claims to decrease human contact with wheel set components and machines, improve personal health and safety, reduce opportunities for error, and eliminate the requirement of forklift operation on the shop floor [50].

\subsection{RAS in Power Transmission Line Maintenance}

A power transmission wire inspection system was developed for Netherlands railway company, which perceives the thickness of wires and detects any appearance of holes that are caused by local sparks [51]. In this system, the under surface of the overhead wire is illuminated with a laser beam and reflected radiation is then detected by a fast CCD detector. The processing algorithm determines the thickness of wire and any of occurrence of holes. According to Smorenburg and Valkenburg, the system is capable of mounting on a train, which travels $90 \mathrm{~km} / \mathrm{h}$ and inspects four wires simultaneously for every centimetre. Hence, the system is able to efficiently execute inspection process without disrupting normal services [51]. In addition, Sawada et al. have developed a fully autonomous robot to inspect power transmission lines-which is capable of negotiating obstacles, such as towers, ground wires, etc. The robot consists of curved arm - which helps to negotiate obstacles, a vehicle assembly that carries the inspection unit, and a balancer with a built-in controller. The robot measures eddy current and the processing algorithm determines the condition of the power transmission wire based on the input data [52]. Besides, Peungsungwal et al. have developed an autonomous power transmission line inspection robots to examine the power cables and insulators [53]. The robot uses image-processing techniques, such as edge detection and pattern recognition algorithms to detect insulators. The most 
interesting feature of this robot is that it does not depend on a battery pack or any other sources of fuel, but harvest the required energy from power line through induction [53].

\subsection{RAS in Track Maintenance}

Railway track maintenance plays a major role in the railway industry. Trivedi et al. have proposed a fully autonomous robotic system to detect and remove sleeper bolts, feed new fastener, and assemble them in Shinkansen high-speed train lines. Instead of creating one massive robot to perform all tasks, researchers have taken a different approach and created a multi-robotic system, where the individual robot will focus on a simplified task. According to Trivedi et al., the system is technically and economically viable [54]. Further, Rowshandel et al have proposed an integrated robotic system for the detection and characterization of rolling contact fatigue cracks in rails. The suggested system consists of a mechanized trolley, a robot, a commercially available alternating current field measurement (ACFM) system, and a laser distance sensor. The trolley, which contains the articulated robot, will travel at a controlled speed scanning for surface cracks on the rail and the robot will take over the scanning process while using the ACFM system once a crack is detected. Further, it has been concluded that the system manages to autonomously detect and characterize surface-breaking defects with high precision [55].

Furthermore, researchers have successfully exploited the recent developments of machine vision and classification algorithms to develop RAS in rail track maintenance tasks, especially for inspection and monitoring [56,57]. Santur et al. have proposed a robust rail condition monitoring methodology while using a laser scanner mounted on a moving rail car, which detects fractures, scorings, and excessive wear of the track. Random Forest classification learning algorithm is used in their system by considering the Eigenvalues of rail profiles as input. According to the authors, the system demonstrates 98\% accuracy [58]. A similar track geometry diagnostic system has been developed by Madejski, which alerts the weak locations of tracks and helps to save about $90 \%-95 \%$ labour consumption [59].

In addition, there are few dozens of RAS that have been developed to detect the missing or worn out track components, such as bolts, clips, ties, tie plates, anchors, and turnout components [60-62]. For example, an autonomous clip detection and classification system was introduced by Gibert et al., where HOG of target images was analyzed to detect clips and classify their condition as good, missing, or broken by taking advantage of Linear Support Vector Machine (LSVM) learning algorithm. The described system is capable of achieving a probability of detection of $98 \%$ and a false alarm rate of $1.23 \%$ [63]. Another application is developed to detect missing railway clips and recently replaces clips that are different in color by employing basic image processing techniques, such as Gaussian filtering, Canny edge detection, suppressing smaller edges from a binary image, analyzing edge pixels density of binary images, and histogram of colors. According to Singh et al., the system is accurate up to $95.3 \%$, $86.5 \%$, and $84.7 \%$ in finding clips, blue clips, and missing clips, respectively [64]. In addition, Li et al present a real-time automatic vision-based rail inspection system, which performs inspections at 16 $\mathrm{km} / \mathrm{h}$ with a frame rate of $20 \mathrm{fps}$ to detect and inspect tie plate, tie, and anchor. The proposed system that is composed with an image and video analysis methodology, which is combined with multiple cameras, Global Position System (GPS) and a distance measurement instrument. The system consists of an acquisition module, rail component detection, optimization module, and an exception detection module to detect damaged or missing components. Further, the systems acquired following detection results, Tie plate: $100 \%$ recall rate and $99.3 \%$ precision, Tie: $82.3 \%$ recall rate and $88.2 \%$ precision, and Anchor: more than $96 \%$ recall rate and precision [65].

A higher technology readiness level robotic solution for rail track inspection is developed by "Autoscan", which uses electromagnetic acoustic transducers (EMATs) that are mounted to a self-powered autonomous inspection cart with a robotic arm. The system is at TRL 6 and it has the ability to reduce track inspection costs by at least $15 \%$. It is expected to record different defects with an accuracy of $+/-0.5 \mathrm{~mm}$ [66]. In addition, a commercially available automated rail inspection robotic platform has been introduced by "RailPod". The platform is composed of a vehicle that can be remotely 
controlled or drive autonomously and it contains the ability to configure based on individual customer need [67].

\subsection{RAS in Bridge Maintenance}

Railway bridge maintenance is labor-intensive and, in most circumstances, technicians need to execute the bulk of tasks in dull, dirty and dangerous environments. Therefore, to relieve human workers from such labour intensive and dangerous tasks, Liu et al. have introduced a robotic system for stripping paint and rust from steel bridges. The proposed system consists of a 6-DOF industrial robot, a moving platform, a sensor package that is equipped with a laser range finder, cameras, and a capacitive sensor network, and a high-performance computer [68]. In addition, Wang and Kawamura have designed and developed a semi-autonomous magnetic climbing robot for steel bridge inspection, which can be freely moved without disrupting the traffic. The magnetic wheels of this design not only provide necessary adhesion, but the required magnetic field for inspection. The system is yet to be completed and tested on real bridge inspection task [69]. Furthermore, Oh et al. have prototyped a bridge inspection robot, which consists of a specially designed car, a guide rail, and an inspection robot. The proposed system is capable of fully autonomous operation or teleoperation by distant user, which has been successfully tested in laboratory conditions. It is expected to develop the robot to operate in real environments [70].

\subsection{RAS in Tunnel Maintenance}

The majority of railway tunnels are inspected by human technicians and that suffers from human errors, costs, and high inspection time [71]. Further, atmospheric conditions within tunnels are characterized as dusty, humid, and dark, which acts as hazardous and hostile environments for human workers [72]. IRIS Hyrail by Penetradar is a commercially available semi-autonomous tunnel inspection system, which consists of a Ground-penetrating radar (GPR). The inspection module is fixed to a motorized boom, which is mounted on a vehicle that can be driven on the rail tracks. The manufacturer provides specialized software to manage, collect, and display GPR data [73]. In addition, Aoshima et al. have proposed an automatic tunnel inner wall deterioration monitoring system. The suggested scheme consists of sensors that are fused to regular train (velocity more than $100 \mathrm{~km} / \mathrm{h}$ ) which is then used capture data on daily basis. The system is capable of scheduling the necessary maintenance upon the detection of any deterioration being discovered by analysing the relationship between the train velocity and the cross-correlation coefficient of the interpolated crack images [71].

\subsection{RAS in other Railway Maintenance Tasks}

RAS in other railway maintenance tasks include automated cleaning robots in train stations, monitoring of railway infrastructure using drones, monitoring and inspection of grade crossing at etc. Hiroshi has introduced two mobile cleaning robots, to clean stations in the East Japan Railway Company [28]. One robot is designed to sweep the and collect the dust that accumulated in the corners of station floor and another robot is designed to scrub the station floor. The sweeper type robot has three operational modes, namely 'magnetic guide method', where the robot follows the path of a magnetic tape, 'direct teaching method', where the robot memorizes the path taught by an operator, and a 'wall surface copy system', where the robot follows the wall while using ultrasonic distance sensors.

The second robot, by Hiroshi, is capable of sprinkling water, scrubbing the floor, and removing consumed water by suction. The robot is fixed with a self-propelled system that includes a gyroscope in order to cope with wider station concourse. This robot consists of two operating modes, 'area set up mode', where the robot cleans the input length and width of the area and 'route map mode' where the robot cleans according to a built-in map. The area clean mode has the obstacle avoidance capability, while the built-in map mode does not. Furthermore, it is possible to upload up to nine built-in maps. Both of these robots consist of safety features, such as optical sensors to detect the presence of humans, 
melody chime, alarm lamp, emergency stop switches, and soft bumpers. A similar commercially available cleaning robot for various industrial applications, including railway platforms, is available at "Robotics Inventions" under original equipment manufacturer license. The system claims to have military grade autonomy and mapping capabilities, automated recognition of dirt type to be cleaned, and auto-service station with recycled water tank [74].

Besides, Flammini et al. have evaluated the drone capabilities in a railway-monitoring framework, which include structural health monitoring, such as bridge, tunnel, and other infrastructure inspection, track monitoring, and inspection to detect any faults or disturbances. Authors have presented several potential control and communication frameworks for the drones and claim that drones could represent a promising technology to efficiently monitor railway and mass transit infrastructures [75]. In addition, Ranganathan and Olson have proposed an automated grade crossing condition monitoring system. The required sensors are mounted to a vehicle and the developed algorithm is capable of processing data on the go. The presented system is able to identify a grade crossing with $90 \%$ accuracy while using SVM and identify any dangerous traffic flow lines/regions based on the surface profile of the grade crossing [76,77].

A robotized, semi-automated platform is introduced in $[78,79]$ to collect different safety parameter measurements that are linked to railway track circuits (TC). A system architecture, together with a virtual instrumentation and mathematical model, is presented. It has been concluded that the proposed system can become a viable solution for TC maintenance. Authors claim that this system would be an efficient solution for current manual maintenance practice and aim to improve the operator safety and reduce human errors.

Railway maintenance as a whole is typically a large and complex system. Therefore, these tasks needs to be scheduled in an effective way to improve safety, reduce downtimes, eliminate corrective maintenance jobs, optimize asset/equipment life cycle, and reduce costs. One approach to overcome this challenge is to exploit a data rich environment of railway and introduce autonomous scheduling for maintenance jobs. In [80], an automated task scheduling scheme is introducing by fusing data on railway's condition, planning, and costs. Here, a proof of concept is developed to validate the system and test algorithm functionality. Its authors conclude that the demonstrator found to be viable fit for the purpose. It is expected to conduct further research and evaluate commercial exploitation of the system. A similar system is introduced in [81]. Here, a genetic algorithm is used to optimize railway track maintenance and renewal job scheduling. The system was demonstrated to perform well and illustrated the ability to instead use corrective maintenance activities.

\section{Discussion}

The study reveals a strong case for the necessity of RAS in railway maintenance to improve the safety of passengers and railway workers, quality and reliability of the service, and to mitigate unpredicted expenses through preventive maintenance. It has been revealed that the majority of RAS developments focus on rolling-stock and rail track maintenance tasks, which are justifiable, as said constituents play a major role in the railway industry. Further, it has been realized that the majority of RAS developments in the subject area focus on inspection and monitoring, which are maintain the advantage of computer vision and supervised machine learning algorithms. Therefore, it would be advantageous if more research were conducted on applied robotics to elevate the mechanical engineering aspect of such systems. For instance, introduce collaborative robots to support maintenance technicians in railway depots [82], develop a robotic system to conduct scheduled maintenance tasks, such as front end inspection and service of rolling-stocks or to service rolling-stock brake system, equip railway workers who handle heavy tasks with load carrying exoskeletons to minimize muscular fatigues [83], or adopt humanoid robots from service robotic sector to handle complex railway maintenance tasks $[77,84,85]$.

On the other hand, the majority of inspection tasks tend to exploit SVM, which is a supervised machine algorithm to detect the presence of components or to classify the condition of a component 
as good or damaged. For example, there are several applications for detecting missing bolts and screws, but it emerges that there is not enough research to detect a loose screw or bolt. Further, more examinations are required to exploit different classification algorithms other than SVM in the railway maintenance field. In addition, the detection of smaller railway components in unstructured and dynamic environments is non-trivial. For instance, the detection and localization of connectors of the automatic train coupler electric head pins or detection of wire-locks used to secure drain/filler plugs in certain rolling-stock gearboxes, such as Siemens Class 380 [14].

Furthermore, it is required to make robotic systems as flexible as possible while using off the shelf robots than introducing fully customized designs that yield higher costs, deficit in flexibility, and longer development periods [79]. Flexible and easily reconfigurable RAS developments will provide the ability to deploy the RAS in multiple tasks to attain benefits, such as shorter financial recovery periods and space saving. Further, such systems are viable through the proper design of layout, path planning, and development of intelligent and reconfigurable end of arm tooling. For instance, deploy a robot mounted on a rail or a scissor lift to clean train cab front and inspect automatic train coupler or utilize a robot that is mounted on a moveable platform to perform both transmission fluid and brake service tasks.

\section{Conclusions}

Not to overlook the rapid progress made by RAS in railway maintenance sector, there are still ample areas to be investigated. Authors of the paper believe that, in the near future there will be collaborative robots working together with human workers in railway maintenance. Lastly, the introduction of RAS for railway maintenance cannot be a viewed as a sole responsibility of academic researchers, operations, maintenance, or industrial engineers. For instance, rolling-stock designers and manufacturers should consider promising areas to introduce RAS in rolling-stock maintenance and incorporate strategies to their future designs - which will enable the realization autonomous maintenance systems. In other words, designed and manufactured for automated maintenance.

Author Contributions: All three authors have contributed equally for this article.

Funding: This research received no external funding.

Acknowledgments: This work is supported by Glasgow Caledonian University. Also, authors would like to thank Gary McLachlan of Abellio ScotRail, Glasgow, Roger Harris of Cyber-Weld Ltd, Tony Rodden and Alexandros Gkanatsios at Advanced Forming Research Centre, UK.

Conflicts of Interest: The authors declare no conflict of interest

\section{References}

1. Márquez, A.C. The Maintenance Management Framework: Models and Methods for Complex Systems Maintenance; Springer Science \& Business Media: Berlin, Germany, 2007.

2. Reason, J. Cognitive Engineering in Aviation Domain; Lawrence Erlbaum Associates: Mahwah, NJ, USA, 2000; Volume 72, pp. 102-107.

3. Holmgren, M. Maintenance-related losses at the Swedish Rail. J. Qual. Maint. Eng. 2005, 11, 5-18. [CrossRef]

4. Papaelias, M.; Amini, A.; Huang, Z.; Vallely, P.; Dias, D.C.; Kerkyras, S. Online condition monitoring of rolling stock wheels and axle bearings. J. Rail Rapid Transit 2016, 230, 709-723. [CrossRef]

5. Ciocoiu, L.; Siemieniuch, C.E.; Hubbard, E.-M. From preventative to predictive maintenance: The organisational challenge. J. Rail Rapid Transit 2017, 231, 1174-1185. [CrossRef]

6. Cores, F.; Caceres, N.; Benitez, F.; Escriba, S.; Jimenez-Redondo, N. A logical framework and integrated architecture for the rail maintenance automation. In Proceedings of the European Transport Conference 2013 Association for European Transport (AET), Frankfurt, Germany, 30 September-2 October 2013.

7. ARUP Group. Rail Value for Money Study: Rolling Stock Whole Life Costs; Department for Transport and the Office of Rail Regulation: London, UK, 2011.

8. National Audit Office (NAO). A Short Guide to Network Rail; National Audit Office: London, UK, 2015. 
9. Jimenez-Redondo, N.; Bosso, N.; Zeni, L.; Minardo, A.; Schubert, F.; Heinicke, F.; Simroth, A. Automated and Cost Effective Maintenance for Railway (ACEM-Rail). Procedia Soc. Behav. Sci. 2012, 48, 1058-1067. [CrossRef]

10. Stephen Kent, M.W. Feasibility of the Use of Autonomous Robotic Systems for Wheelset Reworking. Level of Thesis, University of Birmingham, Birmingha, UK, 2017.

11. Preston, J.; Wall, G.; Batley, R.; Ibáñez, J.; Shires, J. Impact of delays on passenger train services: Evidence from Great Britain. Transp. Res. Rec. 2009, 2117, 14-23. [CrossRef]

12. Eversholt Rail Group RDG Angel Trains Porterbrook. Long Term Passenger Rolling Stock Strategy for the Rail Industry [Internet]. Rail Delivery Group. 2017. Report No.: 5. Available online: https://www.midlandsrail. co.uk/wp-content/uploads/2017/04/Rolling-Stock-Strategy-5th-ed.-2017-published-by-RDG.pdf (accessed on 8 February 2019).

13. Brage-Ardao, R.; Graham, D.J.; Anderson, R.J. Determinants of rolling stock maintenance cost in metros. J. Rail Rapid Transit 2016, 230, 1487-1495. [CrossRef]

14. Vithanage, R.K.W.; Harrison, C.S.; DeSilva, A.K.M. A Study on Automating Rolling-stock Maintenance in the Rail Industry using Robotics. In Proceedings of the 14th International Conference on Informatics in Control, Automation and Robotics, Madrid, Spain, 26-28 July 2017; Volume 2, pp. 278-283.

15. Atherton, M.; Hill, S.; Harrison, D.; Ajovalasit, M. Economic and technical feasibility of a robotic autonomous system for train fluid servicing. J. Rail Rapid Transit 2019, 0954409719830520. [CrossRef]

16. Sanne, J.M. Framing risks in a safety-critical and hazardous job: Risk-taking as responsibility in railway maintenance. J. Risk Res. 2008, 11, 645-658. [CrossRef]

17. Feng, H.; Jiang, Z.; Xie, F.; Yang, P.; Shi, J.; Chen, L. Automatic fastener classification and defect detection in vision-based railway inspection systems. IEEE Trans. Instrum. Meas. 2014, 63, 877-888. [CrossRef]

18. Moura, J.; Erden, M.S. Formulation of a control and path planning approach for a cab front cleaning robot. Procedia Cirp. 2017, 59, 67-71. [CrossRef]

19. Itoh, K.; Andersen, H.B.; Seki, M. Track maintenance train operators' attitudes to job, organisation and management, and their correlation with accident/incident rate. Cogn. Technol. Work 2004, 6, 63-78. [CrossRef]

20. Singh, S.; Kumar, R.; Barabadi, A.; Kumar, S. Human error quantification of railway maintenance tasks of disc brake unit. In Proceedings of the World Congress on Engineering 2014, London, UK, 2-4 July 2014.

21. McNulty, R. Realising the Potential of GB Rail: Final Independent Report of the Rail Value for Money Study; Department for Transport and the Office of Rail Regulation: London, UK, 2011.

22. Technical Strategy Leadership Group (TSLG). The Future Railway: The Industry's Rail Technical Strategy 2012 Supporting Railway Business; Technical Strategy Leadership Group \& Rail Safety and Standards Board: London, UK, 2012.

23. Taylor, M.; Westwood, M.; Peters, A. A modular approach to automation of condition monitoring and repair for rail. In Proceedings of the 7th IET Conference on Railway Condition Monitoring (RCM), Birmingham, UK, 27-28 September 2016; pp. 1-6.

24. Rail Research UK Association (RRUKA). Applications of Robotics and Autonomous Systems to Rolling Stock Maintenance; Rail Research UK Association: London, UK, 2015.

25. Shioya, A.; Sasama, H. Inspection robots for railways in Japan. Adv. Robot. 1988, 3, 221-227. [CrossRef]

26. Martland, C.D. Analysis of the potential impacts of automation and robotics on locomotive rebuilding. IEEE Trans. Eng. Manag. 1987, EM-34, 92-100. [CrossRef]

27. Wiercienski, W.; Leek, A. Feasibility of robotic cleaning of the undersides of Toronto subway cars. In Proceedings of the IEEE 39th Vehicular Technology Conference 1989, San Francisco, CA, USA, 1-3 May 1989; pp. 884-887.

28. Yaguchi, H. Robot introduction to cleaning work in the East Japan Railway Company. Adv. Robot. 1995, 10, 403-414. [CrossRef]

29. Xu, H.; Xue, K.; Yu, S.; Gao, X.; Qing, C.; Wei, R. Control for an Innovative Robotics Platform of Rinsing System for Vehicles of Urban Mass Transit. In Proceedings of the 2007 4th IEEE International Conference on Mechatronics, Changchun, China, 8-10 May 2007; pp. 1-6.

30. Tomiyama, T.; García, L.R.; Kršlin, A.; Taykaldiranian, G. Systems and conceptual design of a train cab front cleaning robot. Procedia Cirp 2017, 59, 61-66. [CrossRef] 
31. Khatib, O.; Burdick, J. Motion and force control of robot manipulators. Robotics and Automation. In Proceedings of the 1986 IEEE International Conference on Robotics and Automation, San Francisco, CA, USA, 7-10 April 1986; pp. 1381-1386.

32. Khatib, O. A unified approach for motion and force control of robot manipulators: The operational space formulation. IEEE J. Robot. Autom. 1987, 3, 43-53. [CrossRef]

33. Farnsworth, M.; Tomiyama, T. Capturing, classification and concept generation for automated maintenance tasks. CIRP Ann. Manuf. Technol. 2014, 63, 149-152. [CrossRef]

34. Vithanage, R.K.; Harrison, C.S.; DeSilva, A.K. Enhance 3D Point Cloud Accuracy Through Supervised Machine Learning for Automated Rolling Stock Maintenance: A Railway Sector Case Study. In Proceedings of the 2018 International Conference on Computing, Electronics \& Communications Engineering (iCCECE), Southend, UK, 16-17 August 2018; pp. 242-246.

35. Kilian, K.; Kilian, M.; Mazur, V.; Phelan, J. Rethinking reliability engineering using machine vision systems. J. Rail Rapid Transit 2016, 230, 1006-1014. [CrossRef]

36. Steets, P.G.; Tse, Y.H. Conrail's integrated automated wayside inspection. In Proceedings of the 1998 ASME/IEEE Joint Railroad Conference, Philadelphia, PA, USA, 16 April 1998; pp. 113-125.

37. Asplund, M.; Gustafsson, P.; Nordmark, T.; Rantatalo, M.; Palo, M.; Famurewa, S.M.; Wandt, K. Reliability and measurement accuracy of a condition monitoring system in an extreme climate: A case study of automatic laser scanning of wheel profiles. J. Rail Rapid Transit 2014, 228, 695-704. [CrossRef]

38. Hart, J.; Resendiz, E.; Freid, B.; Sawadisavi, S.; Barkan, C.; Ahuja, N. Machine vision using multi-spectral imaging for undercarriage inspection of railroad equipment. In Proceedings of the 8th World Congress on Railway Research, Seoul, Korea, 18 May 2008.

39. Deilamsalehy, H.; Havens, T.C.; Lautala, P.; Medici, E.; Davis, J. An automatic method for detecting sliding railway wheels and hot bearings using thermal imagery. J. Rail Rapid Transit 2017, 231, 690-700. [CrossRef]

40. Schlake, B.W.; Todorovic, S.; Edwards, J.R.; Hart, J.M.; Ahuja, N.; Barkan, C.P. Machine vision condition monitoring of heavy-axle load railcar structural underframe components. J. Rail Rapid Transit 2010, 224, 499-511. [CrossRef]

41. Liu, L.; Zhou, F.; He, Y. Automated status inspection of fastening bolts on freight trains using a machine vision approach. J. Rail Rapid Transit 2016, 230, 1629-1641. [CrossRef]

42. Li, C.; Wei, Z.; Xing, J. Online inspection system for the automatic detection of bolt defects on a freight train. J. Rail Rapid Transit 2016, 230, 1213-1226. [CrossRef]

43. Kim, H.; Kim, W.-Y. Automated thickness measuring system for brake shoe of rolling stock. In Proceedings of the 2009 Workshop on Applications of Computer Vision (WACV), Snowbird, UT, USA, 7-8 December 2009; pp. 1-6.

44. Zhou, F.; Zou, R.; Qiu, Y.; Gao, H. Automated visual inspection of angle cocks during train operation. J. Rail Rapid Transit 2014, 228, 794-806. [CrossRef]

45. Lortie, M.; St-Bruno, Q.; Holmes, E.; UK Burton upon Trent. Automated Inspection Technologies: A New Paradigm for Preventive Maintenance Programs. In Proceedings of the 2014 Rail Conference American Public Transportation Association, Houston, TX, USA, 12-15 October 2014.

46. Edwards, J.R.; Hart, J.M.; Todorovic, S.; Barkan, C.P.; Ahuja, N.; Chua, Z.; Kocher, N.; Zeman, J. Development of machine vision technology for railcar safety appliance inspection. In Proceedings of the International Heavy Haul Conference Specialist Technical Session-High Tech in Heavy Haul, Kiruna, Sweden, 11-13 June 2007; pp. 745-752.

47. Liu, L.; Zhou, F.; He, Y. Automated Visual Inspection System for Bogie Block Key Under Complex Freight Train Environment. IEEE Trans. Instrum. Meas. 2016, 65, 2-14. [CrossRef]

48. Vithanage, R.K.; Harrison, C.S.; De Silva, A.K. Autonomous rolling-stock coupler inspection using industrial robots. Robot. Comput. Integr. Manuf. 2019, 59, 82-91. [CrossRef]

49. Vale. Robot in the Maintenance of Cars [Internet]. 2016. Available online: http://www.vale.com/brasil/EN/ aboutvale/news/Pages/robos-manutencao-vagoes.aspx (accessed on 18 November 2018).

50. Corporation SMT. Automated Material Handling [Internet]. 2015. Available online: https://smtgroup.com/ en/railway-wheel-shop-equipment/automation/automated-material-handling (accessed on 20 Januar 2019).

51. Smorenburg, C.; van Valkenburg, A.L.G. Automatic inspection of railway overhead wires. In Industrial Inspection; International Society for Optics and Photonics: Bellingham, WA, USA, 1989; pp. 107-117. 
52. Sawada, J.; Kusumoto, K.; Maikawa, Y.; Munakata, T.; Ishikawa, Y. A mobile robot for inspection of power transmission lines. IEEE Trans. Power Deliv. 1991, 6, 309-315. [CrossRef]

53. Peungsungwal, S.; Pungsiri, B.; Chamnongthai, K.; Okuda, M. Autonomous robot for a power transmission line inspection. In Proceedings of the 2001 IEEE International Symposium on Circuits and Systems, Sydney, Australia, 6-9 May 2001; pp. 121-124.

54. Trivedi, M.M.; Ng, K.C.; Lassiter, N.; Capella, R. New generation of multirobot systems. In Proceedings of the 1998 IEEE International Conference on Systems, Man, and Cybernetics, San Diego, CA, USA, 14 October 1998; pp. 3342-3346.

55. Rowshandel, H.; Nicholson, G.L.; Davis, C.L.; Roberts, C. An integrated robotic system for automatic detection and characterisation of rolling contact fatigue cracks in rails using an alternating current field measurement sensor. J. Rail Rapid Transit 2013, 227, 310-321. [CrossRef]

56. Mazzeo, P.L.; Nitti, M.; Stella, E.; Distante, A. Visual recognition of fastening bolts for railroad maintenance. Pattern Recognit. Lett. 2004, 25, 669-677. [CrossRef]

57. Resendiz, E.; Hart, J.M.; Ahuja, N. Automated visual inspection of railroad tracks. IEEE Trans. Intell. Transp. Syst. 2013, 14, 751-760. [CrossRef]

58. Santur, Y.; Karaköse, M.; Akin, E. Condition Monitoring Approach Using 3d Modelling Of Railway Tracks With Laser Cameras. In Proceedings of the International Conference on Advanced Technology \& Sciences (ICAT'16), Konya, Turkey, 1-3 September 2016; pp. 132-135.

59. Madejski, J. Autonomous track geometry diagnostics system. J. Mater. Process. Technol. 2004, 157, $194-202$. [CrossRef]

60. Wang, L.; Zhang, B.; Wu, J.; Xu, H.; Chen, X.; Na, W. Computer vision system for detecting the loss of rail fastening nuts based on kernel two-dimensional principal component-two-dimensional principal component analysis and a support vector machine. J. Rail Rapid Transit 2016, 230, 1842-1850. [CrossRef]

61. Zhang, H.; Yang, J.; Tao, W.; Zhao, H. Vision method of inspecting missing fastening components in high-speed railway. Appl. Opt. 2011, 50, 3658-3665. [CrossRef] [PubMed]

62. Marino, F.; Distante, A.; Mazzeo, P.L.; Stella, E. A real-time visual inspection system for railway maintenance: Automatic hexagonal-headed bolts detection. IEEE Trans. Syst. Man Cybern. 2007, 37, 418-428. [CrossRef]

63. Gibert, X.; Patel, V.M.; Chellappa, R. Robust fastener detection for autonomous visual railway track inspection. In Proceedings of the 2015 IEEE Winter Conference on Applications of Computer Vision (WACV), Waikoloa, HI, USA, 5-9 January 2015; pp. 694-701.

64. Singh, M.; Singh, S.; Jaiswal, J.; Hempshall, J. Autonomous rail track inspection using vision based system. In Proceedings of the 2006 IEEE International Conference on Computational Intelligence for Homeland Security and Personal Safety, Alexandria, VA, USA, 16-17 October 2006; pp. 56-59.

65. Li, Y.; Trinh, H.; Haas, N.; Otto, C.; Pankanti, S. Rail component detection, optimization, and assessment for automatic rail track inspection. IEEE Trans. Intell. Transp. Syst. 2014, 15, 760-770.

66. AutoScan Report Summary [Internet]. European Union. 2019. Available online: https://cordis.europa.eu/ project/rcn/203338/reporting/en (accessed on 25 May 2019).

67. RailPod, Inc. RailPod In Action [Internet]. 2015. Available online: https://rail-pod.com/ (accessed on 22 July 2019).

68. Liu, D.K.; Dissayanake, G.; Manamperi, P.B.; Brooks, P.A.; Fang, G.; Paul, G.; Webb, S.; Kirchner, N.; Chotiprayanakul, P.; Kwok, N.M.; et al. A robotic system for steel bridge maintenance: Research challenges and system design. In Proceedings of the 2008 Australasian Conference on Robotics and Automation; Australian Robotics and Automation Association, Canberra, Australia, 3-5 December 2008.

69. Wang, R.; Kawamura, Y. A magnetic climbing robot for steel bridge inspection. In Proceedings of the 11th World Congress on Intelligent Control and Automation (WCICA), Shenyang, China, 29 June-4 July 2014; pp. 3303-3308.

70. Oh, J.-K.; Lee, A.-Y.; Oh, S.M.; Choi, Y.; Yi, B.-J.; Yang, H.W. Design and control of bridge inspection robot system. In Proceedings of the 2007 International Conference on Mechatronics and Automation, Harbin, China, 5-8 August 2007; pp. 3634-3639.

71. Aoshima, S.; Chikamori, T.; Shiraishi, M. Automatic deterioration monitoring system for tunnel wall using fusion sensors on a train-relation between train velocity and cross-correlation coefficient of interpolated crack images. In Proceedings of the 2002 IEEE International Conference on Industrial Technology, Bankok, Thailand, 11-14 December 2002; pp. 416-420. 
72. Balaguer, C.; Montero, R.; Victores, J.; Martínez, S.; Jardón, A. Towards fully automated tunnel inspection: A survey and future trends. ISARC. In Proceedings of the International Symposium on Automation and Robotics in Construction, Sydney, Australia, 9-11 July 2014; IAARC Publications; p. 1.

73. Montero, R.; Victores, J.; Martinez, S.; Jardón, A.; Balaguer, C. Past, present and future of robotic tunnel inspection. Autom. Constr. 2015, 59, 99-112. [CrossRef]

74. Robotics IND, Inc. Revolutionary Robotics Autonomy [Internet]. 2013. Available online: http://www. roboticsinventions.com/productsB2BAuto.jsp (accessed on 22 July 2019).

75. Flammini, F.; Pragliola, C.; Smarra, G. Railway infrastructure monitoring by drones. In Proceedings of the 2016 International Conference on Electrical Systems for Aircraft, Railway, Ship Propulsion and Road Vehicles \& International Transportation Electrification Conference (ESARS-ITEC), Toulouse, France, 2-4 November 2016; pp. 1-6.

76. Ranganathan, P.; Olson, E. Automated safety inspection of grade crossings. In Proceedings of the 2010 IEEE/RSJ International Conference on Intelligent Robots and Systems (IROS), Taipei, Taiwan, 18-22 October 2010; pp. 2149-2154.

77. Sato, F.; Nishii, T.; Takahashi, J.; Yoshida, Y.; Mitsuhashi, M.; Nenchev, D. Experimental evaluation of a trajectory/force tracking controller for a humanoid robot cleaning a vertical surface. In Proceedings of the 2011 IEEE/RSJ International Conference on Intelligent Robots and Systems (IROS), San Francisco, CA, USA, 25-30 September 2011; pp. 3179-3184.

78. Mihai, D.; Chihaia, I.A.; Surugiu, M.C.; Minea, M. Preventive Maintenance of the Railway Infrastructure employing Robotized Platform and Virtual Instrumentation. In Proceedings of the 2018 10th International Conference on Electronics, Computers and Artificial Intelligence (ECAI), Iasi, Romania, 28-30 June 2018; pp. 1-6.

79. Kolberg, D.; Zühlke, D. Lean automation enabled by industry 4.0 technologies. IFAC Pap. 2015, 48, 1870-1875. [CrossRef]

80. Durazo-Cardenas, I.; Starr, A.; Turner, C.J.; Tiwari, A.; Kirkwood, L.; Bevilacqua, M.; Tsourdos, A.; Shehab, E.; Baguley, P.; Xu, Y.; et al. An autonomous system for maintenance scheduling data-rich complex infrastructure: Fusing the railways' condition, planning and cost. Transp. Res. Part C Emerg. Technol. 2018, 89, $234-253$. [CrossRef]

81. Guler, H. Optimisation of railway track maintenance and renewal works by genetic algorithms. Graevinar 2016, 68, 979-993.

82. Nikolaidis, S.; Hsu, D.; Srinivasa, S. Human-robot mutual adaptation in collaborative tasks: Models and experiments. Int. J. Robot. Res. 2017, 36, 618-634. [CrossRef]

83. Zhang, C.; Zang, X.; Leng, Z.; Yu, H.; Zhao, J.; Zhu, Y. Human-machine force interaction design and control for the HIT load-carrying exoskeleton. Adv. Mech. Eng. 2016, 8, 1687814016645068. [CrossRef]

84. Ackerman, E. IHMC'S ATLAS Robot Learning to Do Some Chores; IEEE Spectrum Blog: Piscataway, NJ, USA, 2016.

85. Chestnutt, J.; Lau, M.; Cheung, G.; Kuffner, J.; Hodgins, J.; Kanade, T. Footstep planning for the honda asimo humanoid. In Proceedings of the 2005 IEEE International Conference on Robotics and Automation, Barcelona, Spain, 18-22 April 2005; pp. 629-634.

(C) 2019 by the authors. Licensee MDPI, Basel, Switzerland. This article is an open access article distributed under the terms and conditions of the Creative Commons Attribution (CC BY) license (http://creativecommons.org/licenses/by/4.0/). 